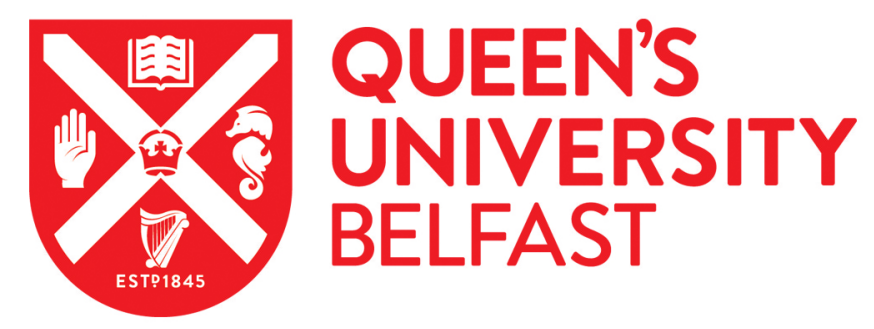

\title{
Measuring Supernatural Belief Implicitly Using the Affect Misattribution Procedure
}

Ross, R. M., Brown-lannuzzi, J. L., Gervais, W. M., Jong, J., Lanman, J. A., McKay, R., \& Pennycook, G. (2020). Measuring Supernatural Belief Implicitly Using the Affect Misattribution Procedure. Religion, Brain, and Behavior, 10(4), 393-406. https://doi.org/10.1080/2153599X.2019.1619620

\section{Published in:}

Religion, Brain, and Behavior

\section{Document Version:}

Peer reviewed version

Queen's University Belfast - Research Portal:

Link to publication record in Queen's University Belfast Research Portal

Publisher rights

(c) 2019 Informa UK Limited, trading as Taylor \& Francis Group. This work is made available online in accordance with the publisher's policies. Please refer to any applicable terms of use of the publisher.

\section{General rights}

Copyright for the publications made accessible via the Queen's University Belfast Research Portal is retained by the author(s) and / or other copyright owners and it is a condition of accessing these publications that users recognise and abide by the legal requirements associated with these rights.

Take down policy

The Research Portal is Queen's institutional repository that provides access to Queen's research output. Every effort has been made to ensure that content in the Research Portal does not infringe any person's rights, or applicable UK laws. If you discover content in the Research Portal that you believe breaches copyright or violates any law, please contact openaccess@qub.ac.uk. 


\section{Measuring Supernatural Belief Implicitly Using the Affect Misattribution Procedure}

Ross, R. M.*a,b, Brown-Iannuzzi, J. L.*c, Gervais, W. M. ${ }^{\mathrm{c}}$, Jong, J. ${ }^{\text {d }}$, Lanman, J. A. ${ }^{\mathrm{e}}$, McKay, R. $^{\mathrm{b}}$, \& Pennycook, G. ${ }^{\mathrm{f}}$

${ }^{a}$ Department of Philosophy, Macquarie University, Sydney, NSW 2109, Australia

${ }^{\mathrm{b}}$ ARC Centre of Excellence in Cognition and its Disorders, Department of Psychology, Royal Holloway, University of London, Egham, Surrey TW20 0EX, UK

${ }^{\mathrm{c}}$ Department of Psychology, University of Kentucky, Lexington, KY 40506, USA

${ }^{\mathrm{d}}$ Centre for Advances in Behavioral Science, Coventry University, Coventry CV1 5FB, UK

${ }^{\mathrm{e}}$ Institute of Cognition and Culture, Queen's University Belfast, Belfast BT7 1NN, UK

${ }^{\mathrm{f}}$ Hill/Levene Schools of Business, University of Regina, Regina SK S4S 0A2, Canada

* These authors contributed equally to this work

Corresponding author: robross46@gmail.com 


\begin{abstract}
Asking about religious beliefs, or lack thereof, is a sensitive and complex issue. Due to cultural norms, people may be motivated to respond in a socially desirable way. In addition, deliberating about beliefs may yield different responses than intuition-based responses. To develop a better understanding of the relationship between intuition and self-reported belief, we developed a new implicit measure of supernatural belief. Specifically, we adapted the Affective Misattribution Procedure (AMP) to measure supernatural belief. In a preregistered online study of 404 American participants, we found that the strength of associations between supernatural entities (e.g., god, devil, heaven) and the concept "real" (as opposed to the concept "imaginary") predicted self-reported supernatural belief and self-reported religious behavior, and these associations were of comparable magnitude to those found in studies where supernatural belief was measured implicitly using the Implicit Association Test (IAT). These results provide provisional evidence that the AMP can be used as an implicit measure of supernatural belief.
\end{abstract}

Keywords: Affect Misattribution Procedure; belief; implicit; prime; religiosity; Semantic Misattribution Procedure; supernatural 


\section{Introduction}

Over the past several decades a rapidly growing body of scholarship has examined the cognitive and evolutionary foundations of religion (Atran, 2002; Barrett, 2004; Boyer, 2001; Johnson, 2015; Norenzayan, 2013). An ongoing challenge for advancing this research agenda is the measurement of supernatural beliefs (Hill \& Pargament, 2017; Mercier, Kramer, \& Shariff, 2018). Researchers typically focus on self-report measures, such as ratings of strength of belief in supernatural entities (e.g., god, devil, heaven) using Likert scales. However, self-report measures do not reveal the full story, as people may not have direct introspective access to their own beliefs and attitudes (Jong, Zahl, \& Sharp, 2017; Nisbett \& Wilson, 1977). Based on dual-process theories of cognition (Evans \& Stanovich, 2013; Gawronski \& Bodenhausen, 2011; Kahneman, 2011; Petty, Briñol, \& DeMarree, 2007), social scientists have recently proposed dual-process theories of religious cognition, according to which self-reported supernatural beliefs are built upon tacit intuitions (Baumard \& Boyer, 2013; Boyer, 2013). In fact, it has been argued that even people who self-identify as atheists may, nonetheless, harbor theistic intuitions (Bering, 2010; Jong, Halberstadt, \& Bluemke, 2012; Uhlmann, Poehlman, \& Bargh, 2008). An additional difficulty for using selfreport measures is that questions about supernatural belief can be especially sensitive: atheism is frequently associated with immorality (Edgell, Hartmann, Stewart, \& Gerteis, 2016; Gervais, Shariff, \& Norenzayan, 2011; Gervais et al., 2017) and, as a consequence, people might overreport supernatural belief. Indeed, a recent study that used an indirect measure revealed that atheism may be considerably underreported in the USA (Gervais \& Najle, 2018).

To address challenges associated with self-report, psychologists have developed performance-based instruments that limit people's ability to strategically control their responses and, thereby, provide further insights into cognitive traits and processes. These instruments are frequently referred to as "implicit measures", in contrast to traditional selfreport "explicit measures" (Gawronski \& Hahn, 2019). Implicit measures are widely used in the social cognition literature - particularly in the literature on intergroup attitudes - and there are data-rich meta-analyses that examine the extent to which different implicit measures of intergroup attitudes predict explicit measures and overt behaviors (Cameron, BrownIannuzzi, \& Payne, 2012; Greenwald, Pehlman, Uhlmann, \& Banaji, 2009; Kurdi et al., 2018; Oswald, Mitchell, Blanton, Jaccard, \& Tetlock, 2013). By contrast, research on religious cognition using implicit measures is in its infancy: there are only a small number of empirical studies, which tend to employ idiosyncratic measures; there are, to date, no meta-analyses; and there are, at present, only tentative proposals about how implicit measures might be related to explicit measures and behavior (Jong et al., 2017).

\subsection{The Implicit Association Test (IAT)}

The most widely used and thoroughly studied implicit measure in the social cognition literature is the Implicit Association Test (IAT). This instrument quantifies the strength of associations between concepts by comparing response latencies when people categorize stimuli (Greenwald, McGhee, \& Schwartz, 1998). The IAT is also the implicit measure that has been used most frequently to study religious cognition (Jong et al., 2017), and at least eight studies have adapted the IAT to measure supernatural belief (Dentale et al., 2018; Farias et al., 2017; Irwin, 2014; Jong et al., 2012; Lindeman, Svedholm-Hakkinen, \& Riekki, 2016; Shariff, Cohen, \& Norenzayan, 2008; Testoni, Visintin, Capozza, Carucci, \& Shams, 
2016; Turpin, Andersen, \& Lanman, 2018). ${ }^{1}$ For example, using a "single target" variant of the IAT (Bluemke \& Friese, 2007; Wigboldus, Holland, \& van Knippenberg, 2006), Shariff et al. (2008) found that the strength of the association between supernatural entities (e.g., god, devil, heaven) and terms associated with "truth" (e.g., actual, genuine, real) was positively associated with self-reported religiosity measures, especially the item "I believe in God". Four of these eight studies tested for correlations between IAT scores and a self-report measure of religiosity or supernatural belief. ${ }^{2}$ And a meta-analysis of these studies provides evidence for a positive association, $r=.24,95 \% \mathrm{CI}[.13, .35], \mathrm{p}<.001 .^{3}$ This association, which is of comparable magnitude to associations between implicit and explicit measures in the social cognition literature (Kurdi et al., 2018), provides provisional evidence that the IAT can be used as an implicit measure of supernatural belief. ${ }^{4}$

Research in the social cognition literature has revealed that implicit measures are only weakly correlated with one another, with explicit measures, and with overt behavior (Bar-Anan \& Nosek, 2014), which has contributed to debates about whether implicit and explicit measures tap into a single, two, or multiple, representational structures (Bar-Anan \& Vianello, 2018; Carruthers, 2018; Greenwald \& Nosek, 2008). By contrast, to date, careful probing of alternative implicit measures of supernatural belief and the extent to which they predict selfreported belief and overt behavior has yet to occur. This inhibits the rigorous testing of theories of religious cognition. Consequently, while the IAT appears to be a promising instrument for studying supernatural belief implicitly, it would be useful if additional implicit measures of supernatural belief were to be developed.

\subsection{The Affect Misattribution Procedure (AMP)}

The Affect Misattribution Procedure (AMP; Payne, Cheng, Govorun, \& Stewart, 2005) is, like the IAT, a widely used implicit measure in the social cognition literature. ${ }^{5}$ In a typical AMP study, participants are briefly presented with a prime (e.g., a picture of a baby), which is followed by an unfamiliar target (e.g., a Chinese pictograph for non-Chinese readers). After a brief interval the target is replaced by a mask and participants are asked to make a judgement about the target while ignoring the prime (e.g., judge whether the Chinese

\footnotetext{
${ }^{1}$ Here we list all published studies that we could find that used the IAT (either the original or "single target" variant) as an implicit measure of supernatural belief. The IAT has also been used to study other religion-related topics, such as, implicit religiosity/spirituality (Bachmann, 2014; Crescentini, Urgesi, Campanella, Eleopra, \& Fabbro, 2014; Klein, Hood, Silver, Keller, \& Streib, 2016; LaBouff, Rowatt, Johnson, Thedford, \& Tsang, 2010; Wenger \& Yarbrough, 2005), categorization of concepts as religious versus paranormal (M. Weeks, Weeks, \& Daniel, 2008; S. R. Weeks \& Gilmore, 2017), and paranormal beliefs not typically promoted by established religions but more associated with "New Age" beliefs (e.g., witchcraft, telepathy, divination; Stieger \& Hergovich, 2013). Given our specific focus on using implicit measures to study supernatural belief, we do not further discuss these other (related) uses of implicit measures in the literature.

${ }^{2} r(59)=.31,95 \%$ CI $[.06, .52], p=.01$ (Shariff et al., 2008); $r(101)=.22,95 \%$ CI $[.03, .40], p<.05$ (Irwin, $2014) ; r(31)=.23,95 \%$ CI $[-.12, .53], p=.20$ (Lindeman et al., 2016); and $r(140)=.22,95 \%$ CI [.06, .37], $p<$ .05 (Dentale et al., 2018).

${ }^{3}$ Conducted used the R package Metafor (Viechtbauer, 2010). Forest plot of the meta-analysis is available in supplement at https://osf.io/a4wnv/ .

${ }^{4}$ There is considerable debate about what implicit measures actually measure (Brownstein, Madva, \& Gawronski, 2019). Some scholars have argued that they do not measure fully fledged "beliefs", but measure some other species of cognitive state, such as "aliefs" (Gendler, 2008), "patchy endorsements" (Levy, 2015), or "unconscious imaginings" (Sullivan-Bissett, 2018). While we do not deny the importance of this debate, for ease of exposition we refer to the measures as "implicit measures of belief" while remaining agonistic about whether the associations being measured really are best described as "beliefs".

${ }^{5}$ For an accessible primer on implicit measures and their strengths and limitations, see Payne and Gawronski (2010).
} 
pictograph is more or less pleasant than average). Studies have shown that affective and semantic judgments about targets are influenced by primes and that the task can, therefore, be used as a measure of the strength of implicit affective and implicit semantic judgments about the prime (Cameron et al., 2012; Payne \& Lundberg, 2014). ${ }^{6}$ For instance, in a study that used an affective version of the task participants rated Chinese pictographs that appear after images of pleasant stimuli as more pleasant than Chinese pictographs that appeared after unpleasant stimuli (Payne et al., 2005). And in a study using a semantic version of the task participants guessed that Chinese pictographs that appeared after images of animate stimuli were more likely to have a meaning in Chinese that refers to animate entities than Chinese pictographs that appeared after inanimate entities (Deutsch \& Gawronski, 2009). Research on implicit social cognition has been facilitated by the development of the AMP (Cameron et al., 2012; Payne \& Lundberg, 2014), and it has played a key role in the development of a new perspective on the relationship between explicit and implicit measures of prejudice (Payne, Vuletich, \& Lundberg, 2017).

The AMP has a number of properties that make it an appealing instrument for research on implicit cognition. It shows good internal consistency and validity (Cameron et al., 2012; Payne \& Lundberg, 2014); it is shorter and more easily understood than the IAT; and, unlike the IAT, it does not rely on response latencies, which can be unduly influenced by outliers. Nonetheless, the AMP has yet to be adapted as an implicit measure of supernatural belief.

\subsection{The present study}

In the present study, we adapted the AMP to examine the strength of peoples' supernatural beliefs implicitly. More specifically, we examined the strength of semantic associations between supernatural entities (e.g., god, heaven, soul) and the concept of "real" (versus the concept "imaginary"). The study of these associations has precedence in the IAT literature: Shariff et al. (2008) used very similar terms as stimuli, and the terms we used were drawn directly from Jong et al. (2012). We predicted that stronger associations between supernatural entities and the concept "real", and weaker associations between supernatural entities and the concept "imaginary", measured using the AMP will be positively associated with selfreported supernatural belief.

\section{Method}

The preregistered analysis protocol, tasks, questionnaires, demographics, supplementary analyses, and raw data are available in a supplement at https://osf.io/a4wnv/ .

\subsection{Participants}

Participants were recruited online via Amazon Mechanical Turk and were paid US\$3 for taking part in the study, which lasted approximately 20 minutes (regarding the sample quality from Amazon Mechanical Turk, see: Horton, Rand, \& Zeckhauser, 2011; Paolacci \& Chandler, 2014; Thomas \& Clifford, 2017). Only people using an American Amazon

\footnotetext{
${ }^{6}$ In the study that introduced the AMP (Payne et al., 2005), participants were asked to make affective judgments (e.g., judgments about the pleasantness of the target). Subsequently, the AMP has been adapted to study semantic judgments (e.g., judgments about the meaning of the target; Deutsch \& Gawronski, 2009). Some scholars (e.g., Sava et al., 2012) refer to the semantic variant of the AMP as the Semantic Misattribution Procedure (SMP). However, the overall structure of the task is essentially unchanged. Consequently, for ease of exposition we refer to both variants of the task as the AMP.
} 
Mechanical Turk account were eligible to participate. The study was approved by the Royal Holloway, University of London ethics procedure, and all participants provided informed consent at the beginning of the study.

In our pre-registration we specified that we would request 500 participants and that if after applying our pre-registered exclusion criteria our sample dropped below 400 we would collect additional blocks of 100 (one block at a time) until we reached our target sample of $400 .^{7}$ After applying exclusion criteria, 404 participants $\left(46.8 \%\right.$ female; $M_{\text {age }}=36.21 ; S D_{\text {age }}=$ 10.79) were retained for analysis. Of these participants, 174 were religiously affiliated (they picked a religious group as their affiliation) and 230 were not (they picked atheist, none, agnostic, or a non-religious group as their affiliation). ${ }^{8}$

\subsection{Procedure}

\subsubsection{Implicit measure of supernatural belief}

We adapted the semantic version of the AMP (Sava et al., 2012) to act as an implicit measure of supernatural belief. In this task, participants are asked to determine whether they think a target image (a Chinese pictograph) means "real" (press the "r" key) or "imaginary" (press the "i" key). ${ }^{9}$ On each trial, participants are randomly presented with one of the 21 primes $(175 \mathrm{~ms}),{ }^{10}$ then a blank screen $(125 \mathrm{~ms})$, then a target image $(100 \mathrm{~ms})$, and finally a visual noise mask that remains on the screen until the participant responds (see Figure 1 for a schematic diagram). ${ }^{11}$ Previous research has established that the Chinese pictographs are neutral and that people appear to misattribute the prime's semantic meaning to the target pictograph (Payne et al., 2005). Each of the 21 primes fell into one of three categories: "real", "supernatural", and "imaginary". The words that represented the real category were real, genuine, existent, actual, true, valid, factual. The words that represented the supernatural category were god, demon, devil, angel, heaven, hell, soul. And the words that represented the imaginary category were imaginary, fake, false, fictional, bogus, untrue, illusory. These 21 primes were selected because they had been used in a study of supernatural belief that used the IAT as an implicit measure (Jong et al., 2012). In total, there were 80 trials. $^{12}$ To

\footnotetext{
${ }^{7} \mathrm{We}$ did not use a formal power analysis to determine sample size as we are employing a novel paradigm and have no strong reason to predict particular effect sizes for the associations between variables. Instead, we selected a minimum sample size of 400 because this fit with our available resources and is a considerably larger sample than the four earlier studies that examined correlations between the IAT and an explicit measure of supernatural belief: $n=33,61,103$, and 142 .

814 participants picked "other" as their affiliation. They were asked to "please specify" in an open response box. We read these responses and coded those that entered specific religious groups as "affiliated" (e.g., "Jehovah's Witness") and those that did not enter specific religious groups as "unaffiliated" (e.g., "spiritual but not religious").

${ }^{9}$ Participants are presented with an instructions screen and a cover story about written Chinese having many different pictographs that mean "real" and "imaginary" (see Supplementary Materials "Survey Flow" document for the instructions screen that includes the cover story).

${ }^{10}$ More precisely, the 21 primes were sampled without replacement. Once all 21 primes had been sampled a further 21 primes were sample without replacement, and so on until all trials had been completed. In total, each participant is presented with 80 different Chinese pictographs.

${ }^{11}$ We sought to present the prime supraliminally because previous research suggests that a quick, yet clear presentation of the prime may enhance the misattribution of emotions/attitudes onto the ambiguous target item (Cameron et al., 2012). To this end, we settled on $175 \mathrm{~ms}$.

12 Our aim was to present each participant with 84 trials; that is, four complete "blocks" of 21 trials without replacement. However, due to a coding error each participant was presented with only 80 trials. This meant that participants do not see all 21 words in the fourth "block" of trials. Nonetheless, because analyses are based on
} 
reduce demand effects, participants are explicitly told that they should not let the prime influence their responses toward targets, as per standard guidelines for using the AMP (Payne et al., 2005; Payne \& Lundberg, 2014). The AMP was presented using the computer software Inquisit v5.0.11 (2016).

\section{--- Insert Figure 1 about here ---}

Figure 1: Schematic diagram of the stimulus sequence in the adapted AMP. Participants are asked to guess whether the Chinese pictograph means "real" (press the " $r$ " key) or "imaginary" (press the "i" key).

For analysis, we generated three indexes of the proportion of times a participant pressed the " $r$ " key when a Chinese pictograph was presented: 1) pictographs preceded by a "real prime", 2) pictographs preceded by a "supernatural prime", and 3) pictographs preceded by an "imaginary prime".

\subsubsection{Self-reported measures of supernatural belief and self-reported religious behavior}

We used the Supernatural Belief Scale-Revised (Jong, Bluemke, \& Halberstadt, 2013; Jong $\&$ Halberstadt, 2016) as a self-report measure of supernatural belief. It is a six-item Likert scale that asks participants about their degree of belief in six supernatural entities associated with conventional religious belief (high God: "There exists an all-powerful and all-knowing spiritual being, whom we might call God"; low gods: "There exist spiritual beings, who might be good or evil, such as angels or demons"; mind-body dualism: "Every human being has a spirit or soul that is separate from the physical body"; afterlife: "There is some kind of life after death"; spirit-matter dualism: "There is a spiritual realm besides the physical one"; and supernatural intervention: "Supernatural events that have no scientific explanation (e.g. miracles) can and do happen"). Previous research found that this measure is a unidimensional scale with high internal consistency (Jong \& Halberstadt, 2016), and in the present study we found it to have high internal consistency (McDonald's $\omega=.97$ ).

We adapted questions from the Religious Landscape Study (Pew Research Center, 2014) as a self-report measure of religious behavior for exploratory analysis. Our adaptation of this scale comprised of three items that asked participants about the frequency of their religious behaviors (attending religious services: "Aside from weddings and funerals, how often do you attend religious services?"; prayer: "Outside of attending religious services, how often do you pray?"; and reading sacred scriptures: "Outside of attending religious services, how often do you read sacred scriptures?"). We found this measure to have high internal consistency (McDonald's $\omega=.90$ ). For ease of exposition, raw scores from the self-report measure of supernatural belief and the self-report measure of religious behaviour were converted to percentage of maximum possible (POMP) scores prior to analysis (Cohen, Cohen, Aiken, \& West, 1999).

The AMP and the self-report measure of supernatural belief are the only measures that appear in pre-registered hypotheses. In addition, we report an exploratory analysis focusing on the self-report religious behavior measure. All other measures in this study were included to generate ideas for further research, not for testing the hypotheses examined in this paper.

mean scores for three categories of prime this minor discrepancy in number of presentations is very unlikely to bias results. 
Consequently, beyond reporting the order of presentation and references for these measures here (and demographics, survey questions, and raw data in a supplement at https://osf.io/a4wnv/ .) we do not report analyses involving these additional measures.

Participants were presented with the following tasks in a fixed order: 1) our adaptation of the AMP, 2) a three-item Cognitive Reflection Test (Shenhav, Rand, \& Greene, 2012), 3) a fouritem Cognitive Reflection Test (Thomson \& Oppenheimer, 2016), 4) a question about whether the participant had previously seen any items from either Cognitive Reflection Test, 5) the six-item self-report measure of supernatural belief (Jong \& Halberstadt, 2016), 6) a single-item question about current religious affiliation, 7) our three-item measure of religious behavior, 8) a single-item question about religious upbringing, 9) a seven-item measure of exposure to credibility enhancing displays (CREDs) of religious belief during up-bringing (Lanman \& Buhrmester, 2017), 10) a single-item question about religious affiliation during upbringing, 11) a two-item measure of beliefs about evolutionary theory (Kahan, 2016), 12) a ten-item version of the "pseudo-profound bullshit" scale (Pennycook, Cheyne, Barr, \& Koehler, 2015), 13) a two-item measure of political attitudes, 14) an instructional manipulation check (Oppenheimer, Meyvis, \& Davidenko, 2009), 15) demographic variables (age, gender, ethnicity, education, income, zip code), 16) four questions about exposure to Chinese pictographs (ability to read Chinese, having studied Chinese, ability to read Japanese, having studied Japanese), and 17) a question about random responding.

\section{Results}

\subsection{Data exclusions}

In total, 497 people completed the study. As recorded in our preregistration document, participants' data were excluded from analysis if any of the following exclusion criteria applied: 1) they had missing data for any item from the self-report measure of supernatural belief or from any trial from the AMP (participants are not able to proceed until they respond to all these tasks, meaning that their data are only removed if an error resulted in their data failing to be recorded) $(n=0), 2)$ they failed the instructional manipulation check (they provided an answer to a general knowledge question after being provided with clear instructions not to answer the question) $(n=29), 3)$ they answered "yes" to a debriefing question asking if they responded randomly to any questions) $(n=29), 4)$ they reported their age to be less than 18 or greater than $100(n=1), 5)$ their IP address matched the IP address of any participant who had already completed the study $(n=6), 6)$ they used only one response key throughout the AMP (earlier research suggests that this should be the only performance-based exclusion criterion for the AMP) $(n=0)$, or 7$)$ they reported that they could read Chinese or Japanese or have studied Chinese or Japanese $(n=28)$. In total, of the 497 participants who completed the study, 93 were removed prior to analysis, meaning that 404 were retained.

\subsection{Hypotheses}

Statistical tests are two-tailed unless otherwise specified, and all one-tailed tests had been pre-registered as being one-tailed. We report descriptive statistics for demographics and variables in a supplement at https://osf.io/a4wnv/ .

\subsubsection{Preregistered analyses}


First, we tested the hypothesis that "real" responses to the Chinese pictograph are most strongly associated with "real" primes (real, genuine, existent, etc.), followed by supernatural primes (god, devil, heaven, etc.), followed by imaginary primes (imaginary, fake, false, etc.). We used a repeated measures ANOVA to test for a main effect of prime on the proportion of times the "real" key was pressed and used planned contrasts to test for differences among these three primes. ${ }^{13} \mathrm{We}$ found an effect of prime, $F(1.60,644.76)=65.04, p<.001, \eta_{p}{ }^{2}=$ 0.14. And, as predicted, the three planned contrasts showed the following: the mean difference for the real minus imaginary comparison was positive, $M_{\text {diff }}=14.21,95 \% \mathrm{CI}$ $[11.12,17.22], p<.001$ (one-tailed); the mean difference for the real minus supernatural comparison was positive, $M_{\text {diff }}=11.03,95 \%$ CI $[8.33,13.73], p<.001$ (one-tailed); and the mean difference for the supernatural minus imaginary comparison was positive, $M_{\text {diff }}=3.18$, $95 \%$ CI $[1.32,5.04], p=.001$ (one-tailed).

Second, we tested the hypothesis that greater self-reported religious belief is associated with a stronger correspondence between the real prime and the supernatural prime in terms of their implicit associations with the concept "real". We calculated a real-supernatural difference score for each participant (i.e., we subtracted the proportion of " $r$ " key responses after a supernatural prime from the proportion of " $r$ " key responses after a real prime) and used a Pearson's correlation to test the hypothesis that this real-supernatural difference score is negatively associated with SBS score. As predicted, the correlation was negative, $r(402)=$ $.19,95 \%$ CI [-.28, -.09], $p<.001$ (one-tailed) (see Figure 2).

\section{--- Insert Figure 2 about here ---}

Figure 2: Scatter plot showing real prime minus supernatural prime difference score (measured using the AMP) as a function of self-reported supernatural belief (percentage of maximum possible score). The line is a line of best fit.

Third, we tested the hypothesis that greater self-reported religious belief is associated with a weaker correspondence between the supernatural prime and the imaginary prime in terms of their implicit associations with the concept "real". We calculated a supernatural-imaginary difference score for each participant (i.e., we subtracted the proportion of " $r$ " key responses after an imaginary word prime from the proportion of " $r$ " key responses after a supernatural word prime), then used a Pearson's correlation to test the hypothesis that this realsupernatural difference score is positively associated with SBS score. As predicted, the correlation was positive, $r(402)=.21,95 \% \mathrm{CI}[.12, .30], p<.001$ (one-tailed) (see Figure 3).

\section{--- Insert Figure 3 about here ---}

Figure 3: Scatter plot showing supernatural prime minus imaginary prime difference score (measured using the AMP) as a function of self-reported supernatural belief (percentage of maximum possible score). The line is a line of best fit.

\subsubsection{Exploratory analyses}

We report correlations among demographics and variables on the Open Science Framework (Table S2). To test the robustness of our pre-registered hypotheses, we made some additional

\footnotetext{
${ }^{13}$ The Greenhouse-Geisser sphericity statistic was $\varepsilon=.797$ and the Huynh-Feldt statistic was $\varepsilon=.800$. Because the Greenhouse-Geisser sphericity statistic is $\varepsilon>.750$ we followed a recommended practice of applying the Huynh-Feldt correction instead of the Greenhouse-Geisser correction (Field, 2017).
} 
comparisons. First, we examined the correlation between proportion of "real" key responses to supernatural primes in the AMP and scores on the SBS. As expected, there was a positive correlation, $r(402)=.33,95 \%$ CI $[.24, .41], p<.001$.

Second, because our hypotheses about the relationship between supernatural belief measured implicitly and explicitly were supported, we explored whether implicit belief predicted a downstream effect of religious belief: religious behavior (i.e., our three-item self-report measure). As expected, self-reported religious behavior was a) negatively correlated with the real-supernatural difference score, $r(402)=-.17,95 \%$ CI $[-.26,-.08], p<.001 ; b)$ positively correlated with the supernatural-imaginary difference score, $r(402)=.23,95 \%$ CI $[.14, .32]$, $p<.001$; and c) positively correlated with the proportion of "real" key responses to supernatural primes, $r(402)=.33,95 \%$ CI $[.24, .41], p<.001$.

Third, we verified that self-reported supernatural belief and self-reported religious behavior are positively correlated, $r(402)=.74,95 \%$ CI $[.69, .78], p<.001$.

\section{Discussion}

A major challenge for studying the cognitive and evolutionary foundations of religion is the measurement of intuitions that subserve self-reported supernatural belief. One proposal for addressing this challenge is to use performance-based implicit measures (Jong et al., 2017; Mercier et al., 2018), as has been done previously in a number of studies that used the IAT. In the present study, we adapted the AMP to examine whether it can, likewise, be used as an implicit measure of supernatural belief. As predicted, we found that supernatural belief indexed using the AMP is positively associated with self-reported supernatural belief and self-reported religious behavior, which provides provisional evidence that the AMP is acting as an implicit measure. Furthermore, the magnitudes of the crucial correlations (ranging from $r=.17$ to $r=.32$ in the expected direction) are comparable to the overall effect size for our meta-analysis that examines the correlation between explicit measures of supernatural belief and the IAT $(r=.24,95 \% \mathrm{CI}[.13, .35])$.

\subsection{Limitations and directions for future research}

This study was conducted in a Western, Educated, Industrialized, Rich, Democratic (WEIRD) context (Henrich, Heine, \& Norenzayan, 2010). Consequently, the degree to which the results generalize beyond culturally WEIRD populations is uncertain. Indeed, there is evidence that cross-cultural variation could prove to be important in the domain of religious cognition. For example, while cognitive style and belief in God show a rather consistent (if modest) association in predominantly North American samples (Pennycook, Ross, Koehler, \& Fugelsang, 2016), recent research suggests greater heterogeneity in effect sizes when more diverse samples are examined (Gervais et al., 2018). We suggest that future studies adapt the AMP (and the IAT) to examine supernatural belief in more culturally diverse societies.

The strength of associations found in the present study are modest, which creates challenges for interpretation. Research in the social cognition literature has likewise found associations between implicit and explicit measures to be modest (Cameron et al., 2012; Greenwald et al., 2009; Kurdi et al., 2018; Oswald et al., 2013) and at least three interpretations of these modest associations have been suggested (Greenwald \& Banaji, 2017). Below, we briefly discuss how these three interpretations from the social cognition literature might apply to our research on supernatural cognition and account for the modest effect sizes. 
First, it has been suggested that implicit measures or explicit measures (or both) may lack validity. In the present study, it seems unlikely that the explicit measure of supernatural belief that was used lacks validity as it has been thoroughly investigated and appears to have good psychometric properties (Jong et al., 2013; Jong \& Halberstadt, 2016). By contrast, we cannot be confident that our adaptation of the AMP is a valid implicit measure of supernatural belief. The psychometric properties of the AMP, and the extent to which intentionally responding to the primes by some proportion of participants might influence results, continues to be examined and debated in the social cognition literature (Bar-Anan \& Nosek, 2012; Gawronski \& Ye, 2014; Mann, Cone, Heggeseth, \& Ferguson, 2019; Payne et al., 2013; Teige-Mocigemba, Penzl, Becker, Henn, \& Klauer, 2016). Given that our study is the first to use the AMP to measure supernatural belief implicitly, it would be advisable for future research to examine its validity more thoroughly by adapting approaches from the social cognition literature.

Second, it is possible that the research context could influence responses on explicit measures but not implicit measures, or vice versa. In the present study, the research context strikes us as relatively "neutral" (an anonymous online study), but further work could examine whether associations become larger (or smaller) in different contexts, such as by using priming paradigms that have been paired with the IAT to study supernatural belief implicitly (e.g., Jong et al., 2012; Shariff et al., 2008) and by conducting studies in environments in which religion is made salient (e.g., places of religious worship).

Third, it has been argued that implicit and explicit measures might tap distinct representational structures rather than be different manners in which the same representational structures get expressed (Bar-Anan \& Vianello, 2018; Greenwald \& Nosek, 2008). This possibility is particularly relevant in the context of religious cognition because there is ongoing debate about representational structures. According to dual-process models of religious cognition, supernatural beliefs are reflective elaborations of implicit supernatural intuitions (Baumard \& Boyer, 2013; Boyer, 2013). Competing with this account is a provocative proposal that people's putative reports of their religious beliefs are not reports of their beliefs at all; rather they are reports of religious credences - qualitatively different and more mutable types of cognitive states (van Leeuwen, 2014, but see Boudry \& Coyne, 2016; Levy, 2017). One potentially fruitful direction for further research could be to examine whether experimental manipulations have differing effects on explicit and implicit measures of supernatural belief. Tentative evidence for this possibility - and therefore support for multiple representational structures - comes from a study that found that making death salient can, in some cases, have different effects on explicit and implicit measures of supernatural belief (Jong et al., 2012).

\subsection{Summary}

In this study we adapted the AMP for use as an implicit measure of supernatural belief. We found evidence for predicted relationships between performance in the AMP and a self-report measure of supernatural belief, and an exploratory analysis also found evidence for relationships between performance in the AMP and self-reported religious behavior. We suggest that future research could build on this work to investigate whether performance in implicit and self-report measures of supernatural belief tap into a single, two, or multiple representational structures; and whether the associations revealed in the present study generalize to non-WEIRD populations. 
Measuring supernatural belief implicitly 12

\section{Acknowledgements}

This research was generously supported by the Australian Research Council (DP180102384) and the Templeton Foundation (grant no. 60624). The opinions expressed are those of the authors and do not necessarily reflect the views of these funders. 


\section{References}

Atran, S. (2002). In gods we trust: the evolutionary landscape of religion. Oxford, UK: Oxford University Press.

Bachmann, R. E. (2014). Development of a German implicit measure of religiosity. Archive for the Psychology of Religion, 36, 214-232.

Bar-Anan, Y., \& Nosek, B. A. (2012). Reporting intentional rating of the primes predicts priming effects in the affective misattribution procedure. Personality and Social Psychology Bulletin, 38(9), 1194-1208. doi:10.1177/0146167212446835

Bar-Anan, Y., \& Nosek, B. A. (2014). A comparative investigation of seven indirect attitude measures. Behavior Research Methods, 46(3), 668-688. doi:10.3758/s13428-013-04106

Bar-Anan, Y., \& Vianello, M. (2018). A multi-method multi-trait test of the dual-attitude perspective. Journal of Experimental Psychology: General, 147(8), 1264-1272. doi:10.1037/xge0000383

Barrett, J. L. (2004). Why would anyone believe in God? Walnut Creek, CA: Altamira Press.

Baumard, N., \& Boyer, P. (2013). Religious beliefs as reflective elaborations on intuitions: a modified dual-process model. Current Directions in Psychological Science, 22(4), 295300. doi:10.1177/0963721413478610

Bering, J. (2010). Atheism is only skin deep: Geertz and Markusson rely mistakenly on sociodemographic data as meaningful indicators of underlying cognition. Religion, 40(3), 166-168. doi:10.1016/j.religion.2009.11.001

Bluemke, M., \& Friese, M. (2007). Reliability and validity of the Single-Target IAT (STIAT): assessing automatic affect towards multiple attitude objects. European Journal of Social Psychology, 38(6), 977-997. doi:10.1002/ejsp.487

Boudry, M., \& Coyne, J. (2016). Disbelief in belief: on the cognitive status of supernatural beliefs. Philosophical Psychology, 29(4), 601-615.

doi:10.1080/09515089.2015.1110852

Boyer, P. (2001). Religion explained: the evolutionary origins of religious thought. Basic Books: New York, NY.

Boyer, P. (2013). Why “belief” is hard work: implications of Tanya Luhrmann's When God Talks Back. HAU: Journal of Ethnographic Theory, 3(3), 349-357.

Brownstein, M., Madva, A., \& Gawronski. (2019) What do implicit measures measure? WIREs Cognitive Science, e1501. https://doi.org/10.1002/wcs.1501

Cameron, C. D., Brown-Iannuzzi, J. L., \& Payne, B. K. (2012). Sequential priming measures of implicit social cognition: a meta-analysis of associations with behavior and explicit attitudes. Personality and Social Psychology Review, 16(4), 330-350. doi:10.1177/1088868312440047

Carruthers, P. (2018). Implicit versus explicit attitudes: differing manifestations of the same representational structures? Review of Philosophy and Psychology, 9(1), 51-72. doi:10.1007/s13164-017-0354-3

Cohen, P., Cohen, J., Aiken, L. S., \& West, S. G. (1999). The problem of units and the circumstance for POMP. Multivariate Behavioral Research, 34(3), 315-346. doi:10.1207/S15327906MBR3403_2

Crescentini, C., Urgesi, C., Campanella, F., Eleopra, R., \& Fabbro, F. (2014). Effects of an 8week meditation program on the implicit and explicit attitudes toward religious/spiritual self-representations. Conscious and Cognition, 30, 266-280. doi:10.1016/j.concog.2014.09.013

Dentale, F., Vecchione, M., Shariff, A., Verrastro, V., Petruccelli, I., Diotaiuti, P., . . . Barbaranelli, C. (2018). Only believers rely on God? A new measure to investigate 
Catholic faith automatic associations and their relationship with psychological wellbeing. Psychology of Religion and Spirituality, 10(2), 185-194. doi:10.1037/rel0000141

Deutsch, R., \& Gawronski, B. (2009). When the method makes a difference: antagonistic effects on "automatic evaluations" as a function of task characteristics of the measure. Journal of Experimental Social Psychology, 45(1), 101-114. doi:10.1016/j.jesp.2008.09.001

Edgell, P., Hartmann, D., Stewart, E., \& Gerteis, J. (2016). Atheists and other cultural outsiders: moral boundaries and the non-religious in the United States. Social Forces, 95(2), 607-638. doi:10.1093/sf/sow063

Evans, J. S. B. T., \& Stanovich, K. E. (2013). Dual-process theories of higher cognition: advancing the debate. Perspectives on Psychological Science, 8(3), 223-241. doi:10.1177/1745691612460685

Farias, M., van Mulukom, V., Kahane, G., Kreplin, U., Joyce, A., Soares, P., . . Möttönen, R. (2017). Supernatural belief is not modulated by intuitive thinking style or cognitive inhibition. Scientific Reports, 7(1), 15100. doi:10.1038/s41598-017-14090-9

Field, A. P. (2017). Discovering statistics using IBM SPSS Statistics: and sex and drugs and rock ' $n$ ' roll (5 ed.). CA, USA: Sage.

Gawronski, B., \& Bodenhausen, G. V. (2011). The associative-propositional evaluation model. Advances in Experimental Social Psychology, 44, 59-127. doi:10.1016/b978-012-385522-0.00002-0

Gawronski, B., \& Hahn, A. (2019). Implicit measures: procedures, use, and interpretation. In H. Blanton \& G. D. Webster (Eds.), Measurement in social psychology (pp. 29-55). New York, NY: Taylor \& Francis.

Gawronski, B., \& Ye, Y. (2014). What drives priming effects in the Affect Misattribution Procedure? Personality and Social Psychology Bulletin, 40(1), 3-15. doi:10.1177/0146167213502548

Gendler, T. S. (2008). Alief in action (and reaction). Mind \& Language, 23(5), 552-585.

Gervais, W. M., \& Najle, M. B. (2018). How many atheists are there? Social Psychological and Personality Science, 9, 3-10. doi:10.1177/1948550617707015

Gervais, W. M., Shariff, A. F., \& Norenzayan, A. (2011). Do you believe in atheists? Distrust is central to anti-atheist prejudice. Journal of Personalilty and Social Psychology, 101(6), 1189-1206. doi:10.1037/a0025882

Gervais, W. M., van Elk, M., Xygalatas, D., McKay, R., Aveyard, M., Dar-Nimrod, I., .. . Bulbulia, J. (2018). Analytic atheism: a cross-culturally weak and fickle phenomenon? Judgment and Decision Making, 13(3), 268-274.

Gervais, W. M., Xygalatas, D., McKay, R., van Elk, M., Buchtel, E. E., Aveyard, M., . . Bulbulia, J. (2017). Global evidence of extreme intuitive moral prejudice against atheists. Nature Human Behaviour, 1(8), e0151. doi:10.1038/s41562-017-0151

Greenwald, A. G., \& Banaji, M. R. (2017). The implicit revolution: reconceiving the relation between conscious and unconscious. American Psychologist, 72(9), 861-871.. doi:10.1037/amp0000238

Greenwald, A. G., McGhee, D. E., \& Schwartz, J. L. K. (1998). Measuring individual differences in implicit cognition: the implicit association test. Journal of Personality and Social Psychology, 74(4), 1464-1480.

Greenwald, A. G., \& Nosek, B. A. (2008). Attitudinal dissociation: what does it mean? In R. E. Petty, R. H. Fazio, \& P. Briñol (Eds.), Attitudes: insights from the new implicit measures (pp. 65-82). Hillsdale, NJ: Erlbaum.

Greenwald, A. G., Pehlman, T. A., Uhlmann, E. L., \& Banaji, M. R. (2009). Understanding and using the Implicit Association Test: III. meta-analysis of predictive validity. 
Journal of Personality and Social Psychology, 97(1), 17-41. doi:10.1037/a0015575.supp

Henrich, J., Heine, S. J., \& Norenzayan, A. (2010). The weirdest people in the world? Behavioral and Brain Sciences, 33(2-3), 61-135. doi:10.1017/S0140525X0999152X

Hill, P. C., \& Pargament, K. I. (2017). Measurement tools and issues in the psychology of religion and spirituality. In R. Finke \& C. D. Bader (Eds.), Faithful measures: new methods in the measurement of religion (pp. 48-77).

Horton, J. J., Rand, D. G., \& Zeckhauser, R. J. (2011). The online laboratory: conducting experiments in a real labor market. Experimental Economics, 14(3), 399-425. doi:10.1007/s10683-011-9273-9

Inquisit 5 [Computer software]. (2016). Retrieved from https://www.millisecond.com. (2016).

Irwin, H. J. (2014). Paranormal beliefs, spoken and unspoken. Australian Journal of Parapsychology, 14(1), 11-27.

Johnson, D. (2015). God is watching you: how the fear of God makes us human. Oxford, UK: Oxford University Press.

Jong, J., Bluemke, M., \& Halberstadt, J. (2013). Fear of death and supernatural beliefs: developing a new supernatural belief scale to test the relationship. European Journal of Personality, 27, 495-506. doi:10.1002/per.1898

Jong, J., \& Halberstadt, J. (2016). Death anxiety and religious belief: an existential psychology of religion: Bloomsbury Publishing.

Jong, J., Halberstadt, J., \& Bluemke, M. (2012). Foxhole atheism, revisited: the effects of mortality salience on explicit and implicit religious belief. Journal of Experimental Social Psychology, 48(5), 983-989. doi:10.1016/j.jesp.2012.03.005

Jong, J., Zahl, B. P., \& Sharp, C. A. (2017). Indirect and implicit measures of religiosity. In R. Finke \& C. D. Bader (Eds.), Faithful Measures: New Methods in the Measurement of Religion (pp. 78-107). New York, NY: NYU Press.

Kahan, D. M. (2016). 'Ordinary science intelligence': a science-comprehension measure for study of risk and science communication, with notes on evolution and climate change. Journal of Risk Research, 20(8), 995-1016. doi:10.1080/13669877.2016.1148067

Kahneman, D. (2011). Thinking, fast and slow. New York, NY: Farrar, Straus and Giroux.

Klein, C., Hood, R. W., Silver, C. F., Keller, B., \& Streib, H. (2016). Is "spirituality" nothing but "religion"? An indirect measurement approach. In H. Streib \& R. W. Hood (Eds.), Semantics and Psychology of Spirituality (pp. 71-86).

Kurdi, B., Seitchik, A. E., Axt, J. R., Carroll, T. J., Karapetyan, A., Kaushik, N., . . Banaji, M. R. (2018). Relationship between the Implicit Association Test and intergroup behavior: a meta-analysis. American Psychologist, Advance online publication. doi:10.1037/amp0000364

LaBouff, J. P., Rowatt, W. C., Johnson, M. K., Thedford, M., \& Tsang, J.-A. (2010). Developmental and initial validation of implicit measure of religiousness-spirituality. Journal for the scientific study of religion, 49(3), 439-455.

Lanman, J. A., \& Buhrmester, M. D. (2017). Religious actions speak louder than words: exposure to credibility-enhancing displays predicts theism. Religion, Brain \& Behavior, 7(1), 3-16. doi:10.1080/2153599x.2015.1117011

Levy, N. (2015). Neither fish nor fowl: implicit attitudes as patchy endorsements. Nous, 49(4), 800-823. doi:10.1111/nous. 12074

Levy, N. (2017). Religious beliefs are factual beliefs: content does not correlate with context sensitivity. Cognition, 161, 109-116. doi:10.1016/j.cognition.2017.01.012 
Lindeman, M., Svedholm-Hakkinen, A. M., \& Riekki, T. (2016). Skepticism: genuine unbelief or implicit beliefs in the supernatural? Conscious and Cognition, 42, 216-228. doi:10.1016/j.concog.2016.03.019

Mann, T. C., Cone, J., Heggeseth, B., \& Ferguson, M. J. (2019). Updating implicit impressions: new evidence on intentionality and the Affect Misattribution Procedure. Journal of Personality and Social Psychology, 116(3), 349-374. doi:10.1037/pspa0000146

Mercier, B., Kramer, S. R., \& Shariff, A. F. (2018). Belief in God: why people believe, and why they don't. Current Directions in Psychological Science, 27(4), 273-268. doi:10.1177/0963721418754491

Nisbett, R. E., \& Wilson, T. D. (1977). Telling more than we can know: verbal reports on mental processes. Psychological Review, 84(3), 231-259.

Norenzayan, A. (2013). Big gods: how religion transformed cooperation and conflict. Princeton, NJ: Princeton University Press.

Oppenheimer, D. M., Meyvis, T., \& Davidenko, N. (2009). Instructional manipulation checks: detecting satisficing to increase statistical power. Journal of Experimental Social Psychology, 45(4), 867-872. doi:10.1016/j.jesp.2009.03.009

Oswald, F. L., Mitchell, G., Blanton, H., Jaccard, J., \& Tetlock, P. E. (2013). Predicting ethnic and racial discrimination: a meta-analysis of IAT criterion studies. Journal of Personality and Social Psychology, 105(2), 171-192. doi:10.1037/a0032734

Paolacci, G., \& Chandler, J. (2014). Inside the Turk: understanding Mechanical Turk as a participant pool. Current Directions in Psychological Science, 23(3), 184-188. doi:10.1177/0963721414531598

Payne, B. K., Brown-Iannuzzi, J., Burkley, M., Arbuckle, N. L., Cooley, E., Cameron, C. D., \& Lundberg, K. B. (2013). Intention invention and the affect misattribution procedure: reply to Bar-Anan and Nosek (2012). Personality and Social Psychology Bulletin, 39(3), 375-386. doi:10.1177/0146167212475225

Payne, B. K., Cheng, C. M., Govorun, O., \& Stewart, B. D. (2005). An inkblot for attitudes: affect misattribution as implicit measurement. Journal of Personality and Social Psychology, 89(3), 277-293. doi:10.1037/0022-3514.89.3.277

Payne, B. K., \& Gawronski, B. (2010). A history of implicit social cognition: Where is it coming from? Where is it now? Where is it going? In B. Gawronski \& B. K. Payne (Eds.), Handbook of implicit social cognition: Measurement, theory, and applications. (pp. 1-15). New York, NY: Guilford Press.

Payne, B. K., \& Lundberg, K. (2014). The Affect Misattribution Procedure: ten years of evidence on reliability, validity, and mechanisms. Social \& Personality Psychology Compass, 8(12), 672-686.

Payne, B. K., Vuletich, H. A., \& Lundberg, K. B. (2017). The bias of crowds: how implicit bias bridges personal and systemic prejudice. Psychological Inquiry, 28(4), 233-248. doi:10.1080/1047840x.2017.1335568

Pennycook, G., Cheyne, J. A., Barr, N., \& Koehler, D. J. (2015). On the reception of detection of pseudo-profound bullshit. Judgment and Decision Making, 10(7), 549-563.

Pennycook, G., Ross, R. M., Koehler, D. J., \& Fugelsang, J. A. (2016). Atheists and agnostics are more reflective than religious believers: four empirical studies and a meta-analysis. PLOS ONE, 11(4), e0153039. doi:10.1371/journal.pone.0153039

Petty, R. E., Briñol, P., \& DeMarree, K. G. (2007). The Meta-Cognitive Model (MCM) of attitudes: impliciations for attitude measurement, change, and strength. Social Cognition, 25(5), 657-686.

Sava, F. A., MaricuToiu, L. P., Rusu, S., Macsinga, I., Vîrgă, D., Cheng, C. M., \& Payne, B. K. (2012). An inkblot for the implicit ssessment of personality: the Semantic 
Misattribution Procedure. European Journal of Personality, 26(6), 613-628. doi:10.1002/per.1861

Shariff, A. F., Cohen, A. B., \& Norenzayan, A. (2008). The devil's advocate: secular arguments diminish both implicit and explict religious belief. Journal of Cognition and Culture, 8, 417-423.

Shenhav, A., Rand, D. G., \& Greene, J. D. (2012). Divine intuition: cognitive style influences belief in God. Journal of Experimental Psychology: General, 141(3), 423-428. doi:10.1037/a0025391

Stieger, S., \& Hergovich, A. (2013). Together we are strong: explicit and implicit paranormal beliefs predict performance in a knowledge test of paranormal phenomena better than explicit beliefs alone. Personality and Individual Differences, 54(5), 562-565. doi:10.1016/j.paid.2012.10.026

Sullivan-Bissett, E. (2018). Biased by our imaginings. Mind \& Language. Advance online publication. doi:10.1111/mila.12225

Teige-Mocigemba, S., Penzl, B., Becker, M., Henn, L., \& Klauer, K. C. (2016). Controlling the "uncontrollable": faking effects on the affect misattribution procedure. Cognition and Emotion, 30(8), 1470-1484. doi:10.1080/02699931.2015.1070793

Testoni, I., Visintin, E. P., Capozza, D., Carucci, M. C., \& Shams, M. (2016). Implicit image of god: God as reality and psychological well-being. Journal for the Scientific Study of Religion, 55(1), 174-184.

Thomas, K. A., \& Clifford, S. (2017). Validity and Mechanical Turk: an assessment of exclusion methods and interactive experiments. Computers in Human Behavior, 77, 184-197. doi:10.1016/j.chb.2017.08.038

Thomson, K. S., \& Oppenheimer, D. M. (2016). Investigating an alternative form of the Cognitive Reflection Test. Judgment and Decision Making, 11(1), 99-113.

Turpin, H., Andersen, M., \& Lanman, J. A. (2010). CREDs, CRUDs, and Catholic scandals: experimentally examining the effects of religious paragon behavior on co-religionist belief. Religion, Brain \& Behavior, 9(2), 143-155.

doi:10.1080/2153599x.2018.1439087

Uhlmann, E. L., Poehlman, T. A., \& Bargh, J. A. (2008). Implicit theism. In R. M. Sorrentino \& S. Yamaguchi (Eds.), Handbook of Motivation and Cognition across Cultures (pp. 71-94): Academic Press.

van Leeuwen, N. (2014). Religious credence is not factual belief. Cognition, 133(3), 698-715. doi:10.1016/j.cognition.2014.08.015

Viechtbauer, W. (2010). Conducting meta-analysis in R with the metafor package. Journal of Statistical Software, 36(3), 1-48.

Weeks, M., Weeks, K. P., \& Daniel, M. R. (2008). The implicit relationship between religious and paranormal constructs. Journal for the Scientific Study of Religion, 47(4), 599-611.

Weeks, S. R., \& Gilmore, A. (2017). The implicit associations between religious and nonreligious supernatural constructs. The International Journal for the Psychology of Religion, 27(2), 89-103. doi:10.1080/10508619.2016.1265044

Wenger, J. L., \& Yarbrough, T. D. (2005). Religious individuals: evaluating their intrinsic and extrinsic motivations at the implicit level of awareness. The Journal of Social Psychology, 145(1), 5-16. doi:10.3200/SOCP.145.1.5-16

Wigboldus, D. H., Holland, R. W., \& van Knippenberg, A. (2006). Single target implicit associations. Unpublished manuscript, Raboud University, Nijmegen. 